\title{
Medical crisis during pandemic: Career preferences change in medical student
}

\author{
Dian Natalia ${ }^{1}$, Rizma Adlia Syakurah ${ }^{2}$ \\ ${ }^{1}$ Medical Profession Students, Medical Faculty, Sriwijaya University, Palembang, Indonesia \\ ${ }^{2}$ Public Health Faculty, Sriwijaya University, Palembang, Indonesia
}

\begin{abstract}
Article Info
Article history:

Received Mar 13, 2021

Revised Aug 29, 2021

Accepted Sep 10, 2021

Keywords:

Career preference

COVID-19

Indonesia

Medical student

Pandemics

ABSTRACT

The COVID-19 pandemic is a major threat to global education. Incidental emotions of fear and anxiety during pandemic have unconsciously influenced preference and outcome about their future career. This study aimed to assess the effect of the COVID-19 pandemic towards career preference change in medical students. A total of 1,027 responses from all over the medical students in Indonesia were collected from an online questionnaire which was broadcasted through social media from 14th July 2020-21st July 2020. This study was using Fear of COVID-19 Scale (FCV-19S) and Depression Anxiety Stress-Scale-21 (DASS-21) to assess fear of COVID-19, stress, anxiety, and depression. Out of 1,027 respondents, $44.6 \%$ had stressed, $47.8 \%$ had anxiety, and $18.5 \%$ had depression with an average FCV-19S score was 17.1. The result showed that the fear and anxiety of COVID-19 during the pandemic had associated significantly with the career decisions in medical students $(\mathrm{p}=<0.05)$. Indonesian policymakers had to keep in mind that the fear of the COVID-19 pandemic in medical students is due to the high mortality COVID-19 cases of health workers in Indonesia. Health workers need adequate working conditions and specific protection, this requires prompt attention from stakeholders.
\end{abstract}

This is an open access article under the CC BY-SA license.

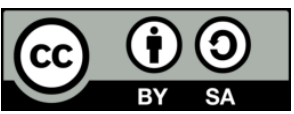

\section{Corresponding Author:}

Rizma Adlia Syakurah

Public Health Faculty

Sriwijaya University

Jl. Raya Palembang-Prabumulih KM. 32 Indralaya, Ogan Ilir, Sumatera Selatan, 30662, Indonesia

Email: rizma.syakurah@gmail.com

\section{INTRODUCTION}

As of early July 2020, the COVID-19 pandemic has infected more than 12,3 million people worldwide and caused quite 550,000 deaths [1]. On 25th July 2020, Indonesia had 95,418 of confirmed cases passed the total of confirmed cases in China, and occupy the ranked 24th out of 222 countries [2]. On 23rd May 2021, Indonesia had 1,775,220 cases and occupied the ranked 18th out of 222 countries [3]. The COVID-19 pandemic threatens physical health, business, economy, and brings unprecedented challenges for people's careers [1], [4].

The COVID-19 pandemic can be viewed as a career shock that significantly effects on an individual's career [5]. Around the world, 278 doctors passed on as a result of COVID-19 after a web search on 15 April, 2020 [6]. The pace of serious disease is twice higher for doctors than for various laborers $(8.1 \%$ versus $4.1 \%$ ) [7]. The workers may likewise encounter expanded tension and dread as a result of the vulnerability they have looked about their future careers [8]. Similarly, the impact of COVID-19 has begun and affects different parts of medical students [4]. A medical crisis like the COVID-19 pandemic will undeniably affect medical students [9]. However, COVID-19 has transformed medical students and medical 
school faculties [4]. Besides applying distance learning for medical students, that actually a new educational concept for them, before the pandemic, $89.5 \%$ of medical students wanted to continue to specialist training after graduation [10], [11]. The career preferences were centered on the three broad clinical departments as the most favored careers, specifically General Surgery, Pediatrics, and Internal Medicine. The influencing factors of the medical students' decision were driven by their capabilities and their expectation [11], [12].

Doctors as the front-liner play clinical roles where they may be at risk of contracting the virus infection, but the risk may differ by specialty [13]. Health workers are needing adequate working conditions and specific protection [7]. Medical career preferences and determinants were a dynamic, complex, and multifactorial process [14]. Self-efficacy theory introduced an approach to understanding a large group of components, known to impact an individual's career decisions. Self-efficacy theory depends on a model of the triad (affective, biological, and cognitive) [15]. Affective states such as emotional arousal like anger, fear, and depression. A higher mental disturbance was found among health workers during the pandemic, and medical students are no exception [7].

Fear of reaching people who are conceivably infected by COVID-19 has been reported [15], [16]. Incidental emotions of fear have unconsciously influenced risk preference and outcome about their future career which is making a drawn-out effect on human psychology [17], [18]. Our emotions are an important part of our decision-making process with an impact on judgment and choice. Fear is related with appraisals of uncertainty, that advancing a risk-avoidant behavior [18]. The existence of the COVID-19 pandemic makes emotional changes to fear that might affect someone to a risk-avoidant behavior and causes the change of specialty preference. Therefore, researchers want to know the pandemic impact on specialty preferences among medical students.

\section{RESEARCH METHOD}

This study is an analytic observational with a cross-sectional methodology directed on a medical student at any stage of education, internship doctor, and fresh graduate, and any institution in Indonesia. Participants obtained by snowball sampling technique who responded to online questionnaires distributed through social media platforms from 14th July 2020 to 21st July 2020.

In this study, the association between psychological factors and career preferences was measured by Fear of COVID-19 Scale (FCV-19S) and Depression Anxiety Stress-Scale-21 (DASS-21). The FCV-19S was utilized in this study to evaluate the fear of the COVID-19 pandemic [19]. The participants show their degree of concurrence with the assertions using a five-item Likert-type scale. Answers included "strongly agree", "strongly disagree", "disagree", "neither agree nor disagree", and "agree". The bottom score feasible for every statement is 1 , and therefore the greatest is 5 . An entire score is determined by summing up every score (ranging from 7 to 35). The greater the fear of the COVID-19 pandemic shows the higher score.

This study also used DASS-21 to assess three factors. This questionnaire consists of 21 items and measures stress, anxiety, and depression in normal, mild, moderate, severe, extremely severe levels. The level of depression is reflected using 0-5 points. The DASS-21 validity was acceptable to excellent ranges. The results have been very positive and are in the range of good to very good for all scales [20]. While, the career preferences divide into three categories, namely hesitancy in career selection, influences career decision, increase certain career interests used "yes" or "no" category.

IBM SPSS Statistics 24 program was accustomed to analyze the variables. Quantitative variables were described by the mean and standard deviation. Qualitative variables were described by frequency distribution. The distribution of qualitative and quantitative variables was compared using the two-tailed Chisquare test. The means of FCV-19S and career preference were compared using an independent T-test $(\mathrm{p}<0.05$ as statistical significance, for all tests).

\section{RESULTS AND DISCUSSION}

The authors collected 1,027 responses from all medical students in Indonesia from online questionnaires, broadcasted through social media from 14th-21st July 2020. Of the 1027 medical students who filled the questionnaire, $678(66 \%)$ were female and $349(34 \%)$ were male with an average age of 23 years. Respondents were dominated by the pre-clinic medical student of $480(46.7 \%)$ respondents. Out of 1027 respondents, $9.7 \%$ of respondents had comorbidity, $26.1 \%$ had done COVID-19 examination, and only $2.2 \%$ of respondents had ever been diagnosed as positive as shown in Table 1.

Figure 1 shows that the most preferred career preferences were pediatrics $(217 ; 26.4 \%)$ followed by obstetric gynecology $(270 ; 26.3 \%)$ and internal medicine $(252 ; 24.6 \%)$. Figure 2 shows the factors that affected students' decisions to opt for their careers. The most frequent reason for choosing a future career was academic interest $(879 ; 85.6 \%)$, followed by opinion about matches with respondent's capabilities (327; $31.8 \%)$. Conversely, $128(12.5 \%)$ medical students reported that they were still undecided to opt for their future careers. 
Table 1. Demography of respondents

\begin{tabular}{llll}
\hline No. & & \multicolumn{1}{c}{ Variable } & $\mathrm{n}(\%)$ \\
\hline 1. & Age, mean \pm SD & & $21.47 \pm 2.283$ \\
2. & Gender & Male & $349(34)$ \\
& & Female & $678(66)$ \\
3. & Educational stage & Pre-clinic & $480(46.7)$ \\
& & Clinical (co-assistant) & $363(35.3)$ \\
& & Internship & $156(15.2)$ \\
4. & Having comorbidity & Fresh graduate & $28(2.8)$ \\
& & Yes & $100(9.7)$ \\
5. & Having family with comorbidity & No & $927(90.3)$ \\
& & Yes & $508(49.5)$ \\
6. & Has done a COVID-19 examination & No & $519(50.5)$ \\
& & Yes & $258(26.1)$ \\
7. & Have ever been diagnosed COVID-19 (+) & No & $759(73.9)$ \\
& & Yes & $23(2.2)$ \\
\end{tabular}

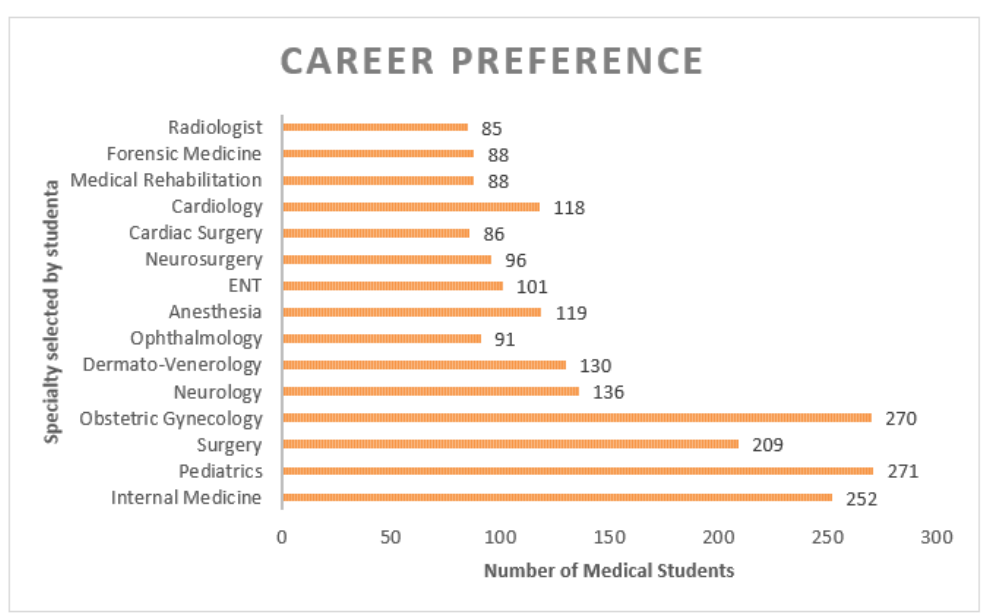

Figure 1. Top 15 most selected careers by medical students $(n=1,027)$

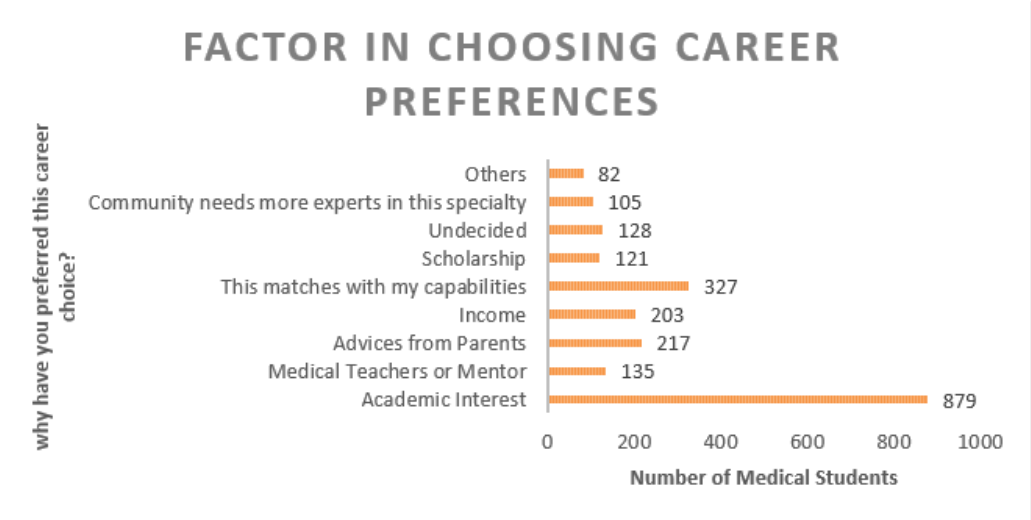

Figure 2. Factors that influence a medical student in choosing their career preferences $(n=1,027)$

Figure 3 shows that the most frequent consideration in determining career preference during the COVID-19 Pandemic was a career with less exposure to COVID-19 (38.6\%) followed by careers that were more needed during the pandemic (35.2\%). However, $519(50.6 \%)$ medical students reported that the COVID-19 pandemic does not affect their career preferences.

Data obtained from the questionnaire were analyzed using Chi-square. Gender is associated significantly with hesitancy in career selection ( $\mathrm{p}$-value <0.05). Educational stage associated significantly with hesitancy in career selection and increasing certain career interests ( $p$-value $<0.05$ ). As shown in Table 2 , 
fear of being infected, transmitting, and death from COVID-19 had a significant association with hesitancy in career selection, influence the career decision, and increase certain career interest ( $p$-value $<0.05)$. The comorbid factors in respondents or their families had a significant impact on career decisions for medical students due to the COVID-19 Pandemic (p-value<0.05). Anxiety had a significant association with the three statements in career preferences ( $\mathrm{p}$-value $<0.05)$. And, depression had a significant association with hesitancy in career selection ( $p$-value $=0.017$ ). Table 2 also shows that there were significant differences in the means of FCV-19S score due to career preferences.

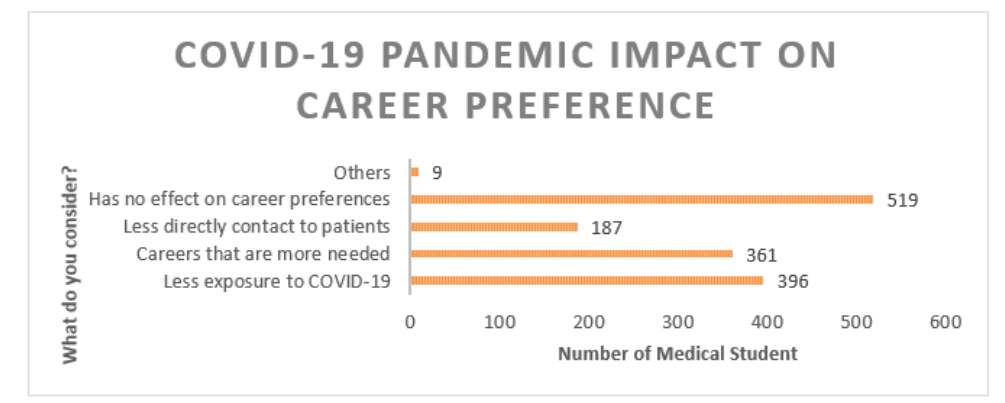

Figure 3. Consideration in determining career preference among medical student during COVID-19 pandemic

Table 2. COVID-19 pandemic and career preference

\begin{tabular}{|c|c|c|c|c|c|c|c|}
\hline \multicolumn{2}{|c|}{ COVID-19 pandemic } & \multicolumn{2}{|c|}{$\begin{array}{l}\text { Hesitancy in career } \\
\text { selection ( } n, p \text { value) }\end{array}$} & \multicolumn{2}{|c|}{$\begin{array}{c}\text { Career preference } \\
\text { Influences career } \\
\text { decision ( } \mathrm{n}, \mathrm{p} \text { value) }\end{array}$} & \multicolumn{2}{|c|}{$\begin{array}{c}\text { Increase certain career } \\
\text { interests ( } n, p \text { value) }\end{array}$} \\
\hline \multirow[t]{2}{*}{ Gender } & Male & 72 & \multirow{2}{*}{$0.001 *$} & 95 & \multirow{2}{*}{0.213} & 165 & \multirow{2}{*}{0.236} \\
\hline & Female & 204 & & 210 & & 347 & \\
\hline \multirow[t]{2}{*}{ Educational stage } & Pre-clinical & 116 & \multirow{2}{*}{$0.036^{*}$} & 138 & & 282 & \multirow{2}{*}{$0.000 *$} \\
\hline & Clinical (co-assistant) & 109 & & 104 & $\Omega 001$ & 163 & \\
\hline Fear being infected of & Yes & 265 & \multirow{2}{*}{$0.000^{*}$} & 288 & \multirow{2}{*}{$0.000^{*}$} & 453 & \multirow{2}{*}{$0.000 *$} \\
\hline COVID-19 during education & No & 11 & & 17 & & 59 & \\
\hline Fear of transmitting COVID- & Yes & 273 & \multirow{2}{*}{$0.000^{*}$} & 300 & $0.001^{*}$ & 492 & \multirow{2}{*}{$0.040 *$} \\
\hline 19 to your surroundings & No & 3 & & 5 & & 20 & \\
\hline Fear of death from COVID- & Yes & 218 & \multirow[t]{2}{*}{$0.000 *$} & 238 & $0.000 *$ & 355 & \multirow[t]{2}{*}{$0.000^{*}$} \\
\hline 19 & No & 58 & & 67 & & 157 & \\
\hline \multirow{2}{*}{$\begin{array}{l}\text { Has done a COVID-19 } \\
\text { examination }\end{array}$} & Yes & 70 & \multirow{2}{*}{0.746} & 77 & & 129 & \multirow{2}{*}{$0.038^{*}$} \\
\hline & No & 206 & & 228 & 0.687 & 393 & \\
\hline Have ever been diagnosed & Yes & 9 & \multirow{2}{*}{0.180} & 8 & & 9 & \multirow{2}{*}{0.298} \\
\hline COVID-19 (+) & No & 276 & & 377 & 0.589 & 503 & \\
\hline \multirow[t]{2}{*}{ Domicile in a high-risk zone } & Yes & 164 & & 181 & & 315 & \\
\hline & No & 112 & $0.044^{*}$ & 123 & 0.515 & 197 & 0.478 \\
\hline Stress & Yes & 136 & & 150 & 0055 & 250 & \\
\hline & No & 140 & 0.067 & 155 & 0.055 & 262 & $0.007 *$ \\
\hline Anxiety & Yes & 164 & & 175 & & 266 & \\
\hline & No & 112 & $0.000^{*}$ & 130 & $0.000^{*}$ & 246 & $0.008^{*}$ \\
\hline Depression & Yes & 63 & $0030 *$ & 65 & 0132 & 103 & 0183 \\
\hline
\end{tabular}

$*$ p-value $<0.05$, using Pearson Chi-square if expected count $<20 \%$ (Table $>2 \times 2$ )

$* *$ p-value $<0.05$, using Independent T-test

The impact of COVID-19 on medical students could be considerable. Medical students were postponed from attending clinical rotations in several teaching hospitals. This postponement could reduce exposure to specific specialties among medical students. In this study, the most preferred specialties were Pediatrics, followed by Obstetric Gynecology, and Internal Medicine. Another study showed that Surgery, Pediatrics, Obstetrics and Gynecology, and Internal Medicine were the most desirable options among medical students [10], [21]. 
The different reasons for the most preferred specialties could be attributed to gender differences. Male students more preferred to specialize in Surgery, the reverse for female students more preferred to specialize in Pediatrics [22]-[25]. Females tend to opt-in fewer specialties such as Pediatrics, General Practice, and Obstetric Gynecology which are characterized by a focus on patient-doctor relations [23]. These results indicate that there is an increased prevalence of Pediatrics and Obstetric Gynecology as the most preferred career among medical students because of the higher percentage of female participants.

The most frequent reason to opt for a future specialty was academic interest followed by their capabilities. Individual interest was the most affecting element in determining students' career decisions [25]. Individual interests such as academic interests were the most well-known reason for opting for a medical career in developing or developed countries [26]. Furthermore, the previous study showed that a portion of the medical students opts for their career because match their abilities. These outcomes have shown that medical students already knew about their capacities and their potential to opt for a career [12], [27].

Conversely, this study showed that $12.5 \%$ of medical students reported that they were still undecided to opt for their future careers. Similar findings had been reported that only $10 \%$ of respondents in the study could not select a specialty [12]. Past studies showed that early specialty exposure in clinical training may stimulate students' academic interest and develop their clinical skills [26]. The experience of working independently as a doctor is a reason to choose their final career [14]. There was a significant association between finishing a clinical rotation to opt for the career specialty [11], [28]. A higher percentage of a pre-clinical medical students in our study could be the reason because they had not finished clinical rotations yet. Therefore, parents or families also became one of the factors for medical students to make decisions about their career preferences [29], [30]. In the collectivist environment, like Indonesia, parents' and elderly's opinions are heavily regarded. Parents' discernment will influence their assessment, because the specific career becoming more critical [30], [31]. This study showed that only nearly one-fourth of students chose advice from parents as the determinant of their career preferences. Most students did not seem to feel the pressure from parents to opt for their future careers. This may be because they are not yet at that stage when they need to talk about it [28].

One of two medical students had symptoms of stress or anxiety. Contrasted with non-health workers, health workers had a higher prevalence of anxiety, depression, and sleeping disorders especially insomnia [29]. The previous study showed that the medical staff has a more significant level of fear, depression, and anxiety than the regular staff [32]. An observational study involving 1,207 Indonesian medical students revealed that almost half of the respondents had symptoms of anxiety during the COVID-19 pandemic [33]. It was possible that medical students also have a higher level of fear or anxiety than other students. With the demands and pressing factors that medical students face, it is nothing unexpected that medical student's psychological, physical, and spiritual wellbeing can be compromised [34]. Higher rates of diagnosed suicidal ideation, mood disorders, and psychological distress were found significantly in medical students [35]. There was a shred of significant evidence that medical students overall experience psychiatric disorders and psychological distress [36]. Despite widespread fear and uncertainty about the COVID-19 pandemic, these results indicate that fear of COVID-19 was associated with career preferences. FCV-19S, fear of being infected, transmitting, death from COVID-19, having comorbid factors, anxiety was significantly associated with career preferences in the medical student during the pandemic. This kind of fear had a significant relationship with hesitancy in career selection, influence the career decision, and increase certain career interests ( $\mathrm{p}$-value<0.05). People with comorbid factors were significantly related to career preferences. Comorbid factors could increase fear of COVID-19 because people with comorbidity have increased mortality risk by five times [37]. This study also showed that there were significant differences in the means of FCV-19S score due to career preferences (p-value<0.05). The higher scores of the FCV-19S show more serious fear of COVID-19 [19].

A pandemic of COVID-19 can form panic, fear, and anxiety rapidly among people overall [19], [38]. This study showed medical students start to consider a career with less exposure to COVID-19 and a career that more needed during the pandemic. Because of the flare-up of COVID-19, fear emerges among health workers in regards to opt their future career [17]. With the high rate of infection and moderate-high mortality, people started worrying about the pandemic. Self-efficacy theory depends on a model of the triad (affective, cognitive, biological) [15]. Affective states such as emotional states like anger, fear, and depression. Fear of contacting people who are potentially infected by COVID-19 has been shown [16], [17]. Many studies have found that incidental emotions such as fear play a huge part in decision-making processes [32] Risk avoidance behavior is a result of fear [18], [39]. Fear of the COVID-19 pandemic had the potential among medical students to change career preferences. The limitation in this study was limited sample representative among medical student at any stage of education, internship doctor, and fresh graduate, and the various of institution. 


\section{CONCLUSION}

This study results showed that the COVID-19 pandemic affects human feelings especially in medical students significantly stuck with various negative perspectives. Thus, anxiety and fear can influence hesitancy in their future career. The Indonesian policymakers should consider this study to help medical students and health workers in Indonesia get better anticipation in the needs to decrease fear of COVID-19 in medical students. The emergence of COVID-19 has disrupted education and this requires prompt attention from stakeholders.

\section{REFERENCES}

[1] World Health Organization (WHO). Coronavirus disease 2019 (COVID-19): Situation report-88. 2020. [Online]. Available: https://www.who.int/publications/m/item/situation-report---88. (accessed Jul. 25, 2020).

[2] Worldometers. COVID-19 coronavirus pandemic reported cases, 2020. [Online] Available: https://www.worldometers.info/coronavirus. (accessed on Jul. 25, 2020).

[3] Worldometers. COVID-19 coronavirus pandemic reported cases, 2020. [Online] Available: https://www.worldometers.info/coronavirus. (accessed on May 23, 2021).

[4] M. N. Ferrel and J. J. Ryan, "The impact of COVID-19 on medical education," Cureus, vol. 12, no. 3, 2020, doi: 10.7759/cureus.7492.

[5] J. Akkermans, J. Richardson, and M. Kraimer, "The Covid-19 crisis as a career shock: Implications for careers and vocational behavior," Journal of Vocational Behavior, vol. 119, Jun. 2020, doi: 10.1016/j.jvb.2020.103434.

[6] E. B. Ing, Q. A. Xu, A. Salimi, and N. Torun, "Physician deaths from corona virus (COVID-19) disease," Occupational medicine (Oxford, England), vol. 70, no. 5, pp. 370-374, 2020, doi: 10.1093/occmed/kqaa088.

[7] A. Nienhaus and R. Hod, "COVID-19 among health workers in Germany and Malaysia," International Journal of Environmental Research and Public Health, vol. 17, no. 13, 2020, doi: 10.3390/ijerph17134881.

[8] M. K. Shoss, "Job insecurity: An integrative review and agenda for future research," Journal of Management, vol. 43, no. 6, pp. 1911-1939, 2017, doi: 10.1177/0149206317691574.

[9] Z. C. Liang, S. B. S. Ooi, and W. Wang, "Pandemics and their impact on medical training: Lessons from Singapore," Academic Medicine, vol. 95, no. 9, pp. 1359-1361, 2020, doi: 10.1097/ACM.0000000000003441.

[10] R. Wiranto and R.A. Syakurah, "Evaluation of implementation and satisfaction of distance learning among medical students during COVID-19 pandemic in Indonesia," International Journal of Research in Medical Sciences, vol. 8, no. 12 , pp. 4212-4218, 2020, doi: 10.18203/2320-6012.ijrms20205291.

[11] E. N. Ossai, K. A. Uwakwe, U. C. Anyanwagu, N. C. Ibiok, B. N. Azuogu, and N. Ekeke, "Specialty preferences among final year medical students in medical schools of southeast Nigeria: Need for career guidance," BMC Medical Education, vol. 16, no. 1, pp. 1-8, 2016, doi: 10.1186/s12909-016-0781-3.

[12] S. Y. Guraya and H. H. Almaramhy, "Mapping the factors that influence the career specialty preferences by the undergraduate medical students," Saudi Journal of Biological Sciences, vol. 25, no. 6, pp. 1096-1101, 2018, doi: 10.1016/j.sjbs.2017.03.019.

[13] M. P. Breazzano, et al., "Resident physician exposure to novel coronavirus (2019-nCoV, SARS-CoV-2) within New York City during exponential phase of COVID-19 pandemic: report of the New York City residency program directors COVID-19 research group," MedRxiv. pp. 1-19, 2020, doi: 10.1101/2020.04.23.20074310.

[14] S. J. Querido, D. Vergouw, L. Wigersma, R. S. Batenburg, M. E. De Rond, and O. T Ten Cate, "Dynamics of career choice among students in undergraduate medical courses. A BEME systematic review: BEME Guide No. 33," Medical Teacher, vol. 38, no. 1, pp. 18-29, 2016, doi: 10.3109/0142159X.2015.1074990.

[15] N. E. Betz and G. Hackett, "Career self-efficacy theory: Back to the future," Journal of Career Assessment, vol. 14, no. 1, pp. 3-11, 2006, doi: 10.1177/1069072705281347.

[16] Lin, C. Y. "Social reaction toward the 2019 novel coronavirus (COVID-19)," Social Health and Behavior, vol. 3, no. 1 , pp. 1-2, 2020, doi: 10.4103/SHB.SHB_11_20.

[17] M. S. Mahmud, M. U. Talukder, and S. M. Rahman, "Does 'Fear of COVID-19'trigger future career anxiety? An empirical investigation considering depression from COVID-19 as a mediator," The International Journal of Social Psychiatry, vol. 67, no. 1, pp. 35-45, 2021, doi: 10.1177/0020764020935488.

[18] Q. Yang, S. Zhou, R. Gu, and Y. Wu, "How do different kinds of incidental emotions influence risk decision making?” Biological Psychology, vol. 154, Jul. 2020, doi: 10.1016/j.biopsycho.2020.107920.

[19] D. K. Ahorsu, C. Y. Lin, V. Imani, M. Saffari, M. D. Griffiths, and A. H. Pakpour, "The fear of COVID-19 scale: development and initial validation," International Journal of Mental Health and Addiction, pp. 1-9, 2020, doi: 10.1007/s11469-020-00270-8.

[20] M. M. Antony, P. J. Bieling, B. J. Cox, M. W. Enns, and R. P. Swinson, "Psychometric properties of the 42-item and 21-item versions of the Depression Anxiety Stress Scales in clinical groups and a community sample," Psychological Assessment, vol. 10, no. 2, pp. 176-181, 1998, doi: 10.1037/1040-3590.10.2.176.

[21] H. Dossajee, N. Obonyo, and S. M. Ahmed, "Career preferences of final year medical students at a medical school in Kenya-A cross sectional study,” BMC Medical Education, vol. 16, no. 1, pp. 1-10, 2016, doi: 10.1186/s12909016-0528-1.

[22] L. T. Pedersen, N. H. Bak, A. S. Dissing, and B. H. Petersson, "Gender bias in specialty preferences among Danish medical students: a cross-sectional study," Dan Med Bull., vol. 58, no. 9, 2011. 
[23] P. Mwachaka and E. Mbugua, "Specialty preferences among medical students in a Kenyan university," Pan African Medical Journal, vol. 5, no. 18, pp. 1-13, 2010, doi: 10.4314/pamj.v5i1.56174.

[24] R. A. Syakurah and R. Rosyila, "Medical student career choice's determinants in Asia: a systematic review," International Journal of Public Health Science (IJPHS), vol. 9, no. 1, pp. 57-61, 2020, doi: 10.11591/ijphs.v9i1.20400.

[25] Y. Yang, et al., "Factors influencing subspecialty choice among medical students: a systematic review and metaanalysis," BMJ Open, vol. 9, no. 3, 2019, doi: 10.1136/bmjopen-2018-022097.

[26] J. H. Lefevre, M. Roupret, S. Kerneis, and L. Karila, "Career choices of medical students: a national survey of 1780 students," Medical Education, vol. 44, no. 6, pp. 603-612, 2010, doi: 10.1111/j.1365-2923.2010.03707.x

[27] M. Ibrahim, et al., "What factors influence British medical students' career intentions?" Medical Teacher, vol. 36, no. 12, pp. 1064-1072, 2014, doi: 10.3109/0142159X.2014.923560

[28] S. H. Subba, et al., "Future specialization interests among medical students in southern India," The National Medical Journal of India, vol. 25, no. 4, pp. 226-229, 2012.

[29] W. R. Zhang, et al., "Mental health and psychosocial problems of medical health workers during the COVID-19 epidemic in China," Psychotherapy and Psychosomatics, vol. 89, no. 4, pp. 242-250, 2020, doi: $10.1159 / 000507639$.

[30] A. Jasmon, F. Masturah, N. S. Nugraha, R. A. Syakurah, A. Afifah, and R. Siburian, "Parental influences on medical students' self-efficacy and career exploration in collectivist culture," Journal of Education and Health Promotion, vol. 9, p. 222, 2020, doi: 10.4103/jehp.jehp_86_20.

[31] R.A. Syakurah, Y.S. Prabandari, Widyandana, and T. Bramantoro, Modeling of factors influencing exploration of medical career choices," International Journal of Public Health Science (IJPHS), vol. 10, no. 1, pp. 175-180, 2021, doi: 10.11591/ijphs.v10i1.20513.

[32] S. Aliaga Tinoco, "Síntomas ansiosos y depresivos en población general y personal médico del Hospital Cayetano Heredia asociados a la cuarentena y atención de la pandemia COVID-19 en Lima," Scielo, vol. 83, no. 1, 2020. [Online]. Available: https://hdl.handle.net/20.500.12866/7889.

[33] D. Natalia and R. A. Syakurah, "Mental health state in medical students during COVID-19 pandemic," Journal of Education and Health Promotion, vol. 10, no. 1, p. 208, 2021.

[34] L. Komer, "COVID-19 amongst the pandemic of medical student mental health," International Journal of Medical Students, vol. 8, no. 1, pp. 56-57, 2020, doi: 10.5195/ijms.2020.501.

[35] B. Maser, M. Danilewitz, E. Guérin, L. Findlay, and E. Frank, "Medical student psychological distress and mental illness relative to the general population: a Canadian cross-sectional survey," Academic Medicine, vol. 94, no. 11, pp. 1781-1791, 2019, doi: 10.1097/ACM.0000000000002958.

[36] C. Wilkes, et al., "Wellbeing and mental health amongst medical students in Canada," International Review of Psychiatry, vol. 31, no. 7-8, pp. 584-587, 2019, doi: 10.1080/09540261.2019.1675927.

[37] R. E. Jordan, P. Adab, and K. K. Cheng, "Covid-19: risk factors for severe disease and death," BMJ, 2020, doi: 10.1136/bmj.m1198.

[38] S. M. Lee, W. S. Kang, A.-R. Cho, T. Kim, and J. K. Park, "Psychological impact of the 2015 MERS outbreak on hospital workers and quarantined hemodialysis patients," Comprehensive Psychiatry, vol. 87, pp. 123-127, 2018, doi: 10.1016/j.comppsych.2018.10.003.

[39] C. A. Dorison, J. Klusowski, S. Han, and J. S. Lerner, "Emotion in organizational judgment and decision making," Organizational Dynamics, vol. 49, no. 1, p. 100702, 2020, doi: 10.1016/j.orgdyn.2019.02.004. 